\title{
Exploration of Jacobsen Design Style in the 1950s
}

\author{
Minglei Jiang \\ Neusoft Institute of Guangdong \\ Foshan, Guangdong, China
}

\begin{abstract}
After World War II, Scandinavian design created a kind of design style that adapted to the times and integrated romance and reason based on playing the role of national tradition and learning from foreign functionalism, and such style, which was internationally recognized, got a rapid revival. This period was a period of Danish designer Arne Jacobson to change his design style and a period of his design activities to flourish. With the economic recovery, new technologies and materials appeared internationally. Jacobson played a very important role in the process of introducing these innovations into Denmark. Unlike other designers who put everything into Danish culture and their design process, he absorbed and utilized them by reference, and established a form of expression which can be exchanged.
\end{abstract}

Keywords-industrialization; craft; life; personality; humanistic functionalism

\section{INTRODUCTION}

In the 1950 s, the world economy was struggling to recover from difficulties. This period was the main period in the Scandinavian design growth process. Because of this, the designers in adversity were facing difficulties and serious challenges. For the Danish design, it was a time of change, and Arne Jacobson's design grew up during this period, entering into the period of design activities flourish and the period of design style transformation.

\section{INHERITANCE AND DEVELOPMENT OF TRADITION IN THE PROCESS OF INDUSTRIALIZATION}

After World War II, the reconstruction of Europe got help from the United States, and America's industrial design ideas and industrial production experience also made the European countries benefit. The successful practice of and rapid changes in American business design, especially the post-war industrial design, brought new inspiration and reflection to the future of design in Europe, especially Scandinavia.

The design of the United States attached great importance to the actual benefits of industrial production, instead of fussing too much about the production cost, assembly line efficiency. In other words, it made too much pursuit of products' materiality, without pursuing the symbolic meaning of abstract modeling too much, which was lack of spiritual care for the users.

In the process of design practice, Scandinavian designers found out the problems in American-style design, namely blind pursuit of market share, neglect of design's guidance meaning towards modern life, and obligations should be undertaken to improve people's living quality and so on. They began to pay attention to reflect cultural heritage in design, to be concerned about "national spirit" and "spirit of the times" in design. Moreover, they combined exquisite technology and industrialized mass production to obtain a wide range of market recognition.

As Penny Spark pointed out in the book of Design Consultant, "Germany sells design in the name of science, Italy in the name of art, Scandinavia in the name of craft, and the United States in the name of business. The design concepts of all these countries are necessary in the post-war competitive market environment. And the role of designers is to help develop the design strategy, so that their products can take a place in the market." It can be said that in the context of industrial production, "in the name of context" is almost the consensus among Scandinavian designers.

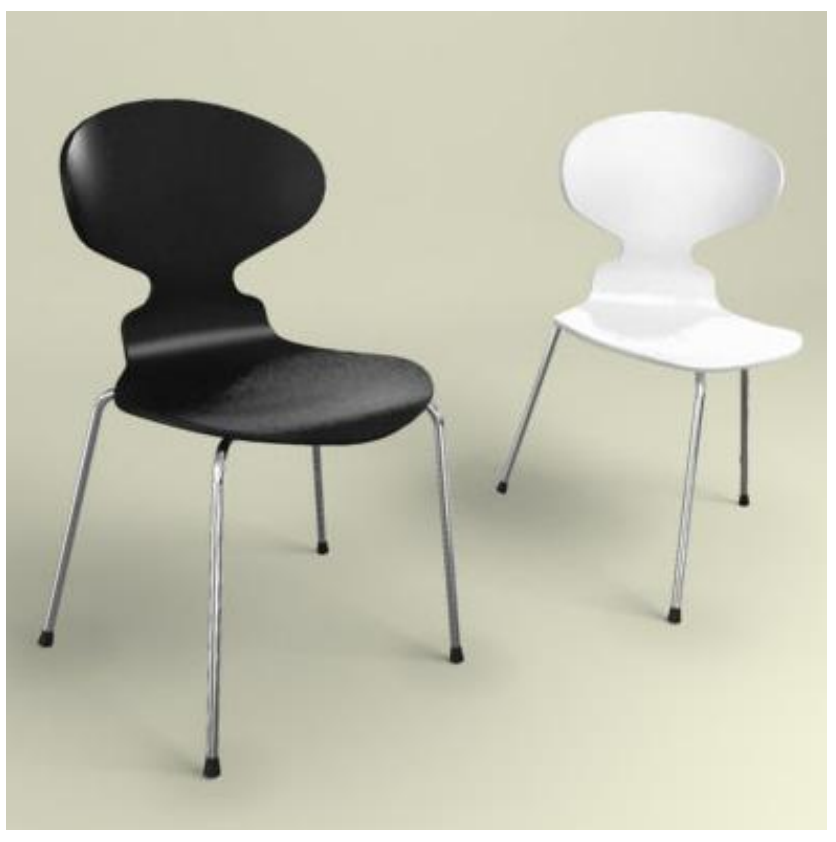

Fig. 1. Danish Arne Jacobson's Ant Chair Design

(The left one is the revised version 1952, the right one is original design 1952)

In 1952, Jacobson completed the design of the most talented creative works - The Ant Chair "Fig. 1". It derived from the advantages of national craft tradition. The design of the main body adopted natural materials and processed the beech and teak by steam molding to form plywood. In addition, this creation also broke through the tradition of Danish 
furniture design, which reduced the details of handicraft modification and adopted the minimalist approach to facilitate the mass production in industrialization, so that the chair parts were reduced to almost the limit, having only two parts: the integrated shape of seat and backrest made by plywood, and three legs made by steel pipe support. In terms of the modeling of seat and backrest, the large arc and the typical Nordic dynamic "smile line" were adopted, which was also the embodiment of traditional exquisite craft.

This work was the first piece of furniture in Denmark that could be produced in an industrialized mass production manner. Its organic shape looked like an ant, which was also the origin of the work's name. Its characteristics, such as flexible and lightweight, foldable storage, easy to be made by mass production, made it one of the best-selling furniture varieties in the twentieth century.

\section{MODIFICATION ON FUNCTIONALISM}

Since the 1920s, European functionalism guided the design and consumption in the form of "form follows function", namely materials and styles must obey the purpose of design. After World War II, the Nordic designers represented by Jacobson practiced boldly, innovated exotic functionalism, integrated the traditional elements of Scandinavian design, such as refine, powerful and clear shape, simple and elegant color, simple, plain and original material and other elements, into functionalism skillfully.

The tableware works "Fig. 2" designed by Jacobson in 1957 clearly reflected this point that the same shape of handle showed the concept of series design, which utilized the extremely simple and moderate radian, and depicted functional characteristics of spoon, knife and fork. Compared with its early tableware "Fig. 3", it seemed that simple design contained the most thoughtful and creative design, pursuing to realize the function completely under the refined situation. It had become a Nordic design model.

Jacobson's design was mainly manifested in the pursuit of sensory pleasure and enjoyment in terms of form and the pursuit of exquisite perfection in terms of technology. Every detail in design carried information and was full of meaning, to refine and correct the unrealistic demands of the original design concept.

As a functionalist, on the one hand, he emphasized the abstract pure geometric form in the design to reflect the pursuit of simple modernity, so that it could be achieved in the industrial production; on the other hand, there was a softening adjustment of the appearance: added elegant and soft curve to the rigid style design that was too rational, or made soft detail processing of the sharp edge, so that the edges and planes could be transformed into S-shaped curve or wavy line, thus forming an "organic" form.

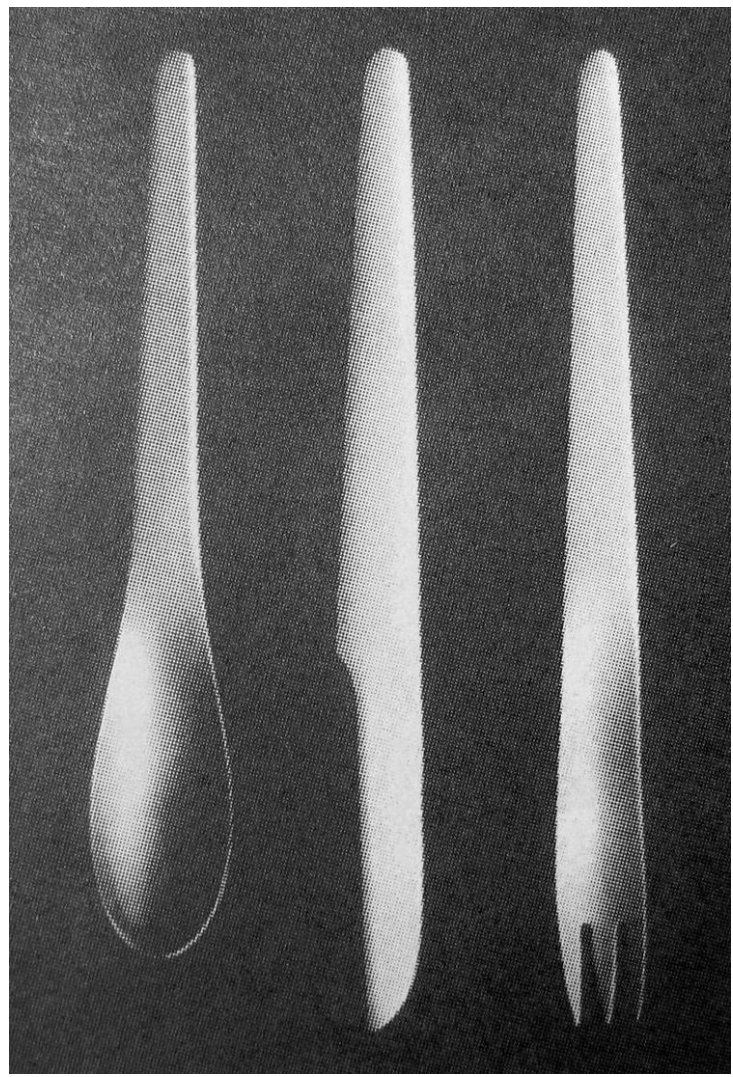

Fig. 2. Danish Arne Jacobson's Tableware Design (1957).

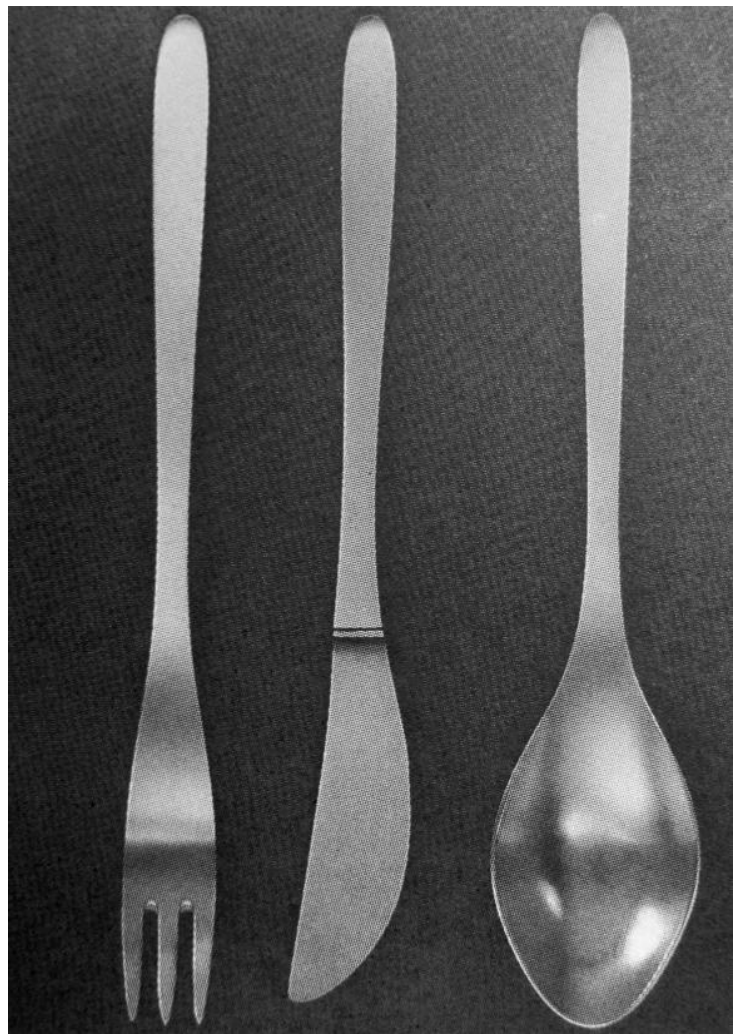

Fig. 3. Danish Arne Jacobson's Tableware Design in the Early Stage 
This form, both visually and mentally, clearly had a more extensive contact with relevant forms existed in the nature with rich human interest, which was easy for people to accept, at the same time, these functionalist products were marked with a clear Scandinavian design imprint. Such modified and softening functionalism which showed the affinity for nature and society was the perfect combination of form and function actually. Therefore, it was appropriately called "humanistic functionalism."

\section{The PURSUIT OF LIFE AND DESIGN PERSONALITY}

Compared to the Italian designers who were romantic, passionate and full of artistic taste, Jacobson was more rigorous, rational and subtle. He inherited the design concept of "For the Beauty of Daily Life", and he acquired artistic inspiration from nature, gradually formed and created a unique form of expression.

During 1956 and 1961, the Egg Chair and the Swan Chair, designed for the Royal Hotel and Scandinavian Airlines, were inspired by the Nordic nature, drawing on the shape of animals "Fig. 4". But he did not mechanically copy the natural form; instead, he conducted art refining to make it an abstract and stylized form.

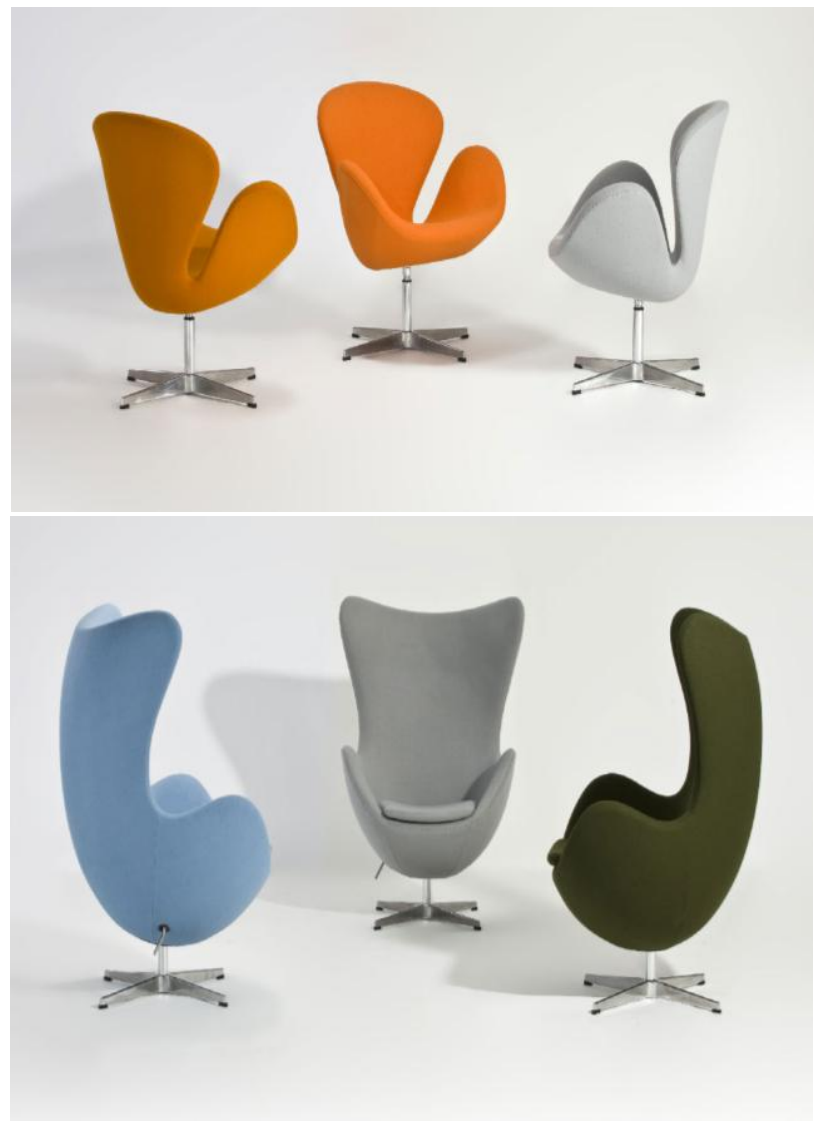

Fig. 4. Danish Arne Jacobson's Swan Chair and Egg Chair (1956-1961)

Although these forms came from nature, they injected eternal beauty into design. The personality of life and design got expression and the beauty of nature and life was peaceful, thus it would not cause riots and disturbances of the senses and mood. The sense of proportion, moderation, expression and tenderness that had been expressed was especially unparalleled elegance, making the audience feel that as if they were facing the perfect itself.

In addition, in these two works, Jacobson explored and tried the new material and technology, boldly made innovation on the modern modeling language, and boldly adopted a chemical synthesis material newly invented. This material could be made into foam sponge shape having good ductility, and it can be taken as the main component of the Egg Chair and Swan Chair in combination with the molded glass fiber. These two seats were designed for a specific indoor environment, and their sculptural organic modeling made them more like a piece of artwork, manifesting the Danish design of the aristocratic style and elegant charm incisively and vividly.

\section{CONCLUSION}

The 1950s was the transitional period of Danish designer Arne Jacobson's design style and flourishing period of his design activities. In this period, with a "critical" learning attitude, he recognized that the abstract geometric form adopted by modernism was beneficial to the standardized and mass industrial production mode on the one hand; on the other hand, he conducted improvement and amendment on the design form that was rigid and completely opposite the natural form, and he added more human factors, created an organic modeling language with a sculptural sense, elegant style and rich flavor.

Jacobson's design works attached much importance to details. He was good at embellishing elegance using the detail design, in order to achieve the overall perfect effect. He paid equal attention to the furniture, furnishings, floors, wall ornaments, lighting fixtures, doors and windows and the overall building and appearance design. For example, when he was designing the Royal Hotel, he designed the building appearance and interior furniture, lighting, and even door handles, the designer also performed careful design. He used polished or matte nickel-plated copper as the material and designed the organic shape suitable for grasping. The elegant shape and fine material were unique.

With the economic recovery, new technologies and materials appeared in the international arena. In the process of introducing these innovations into Denmark, Jacobson played a very important role. The works designed by him used a lot of modern materials and modern molding process. Jacobson designed three classic chairs in the 1950s: The Ant Chair designed for Novo Corporation in 1952; the Swan Chair and Egg Chair designed for the Scandinavian Airlines hotel in 1958; all the chairs were overall molding of hot pressed plywood.

Jacobson's design combined modern design concepts with Danish traditional style, emphasized material application and complete structures, combined the well-designed function with mass production, and established a changeable expression form, making his furniture works have extraordinary and eternal charm. His comprehensive achievements in terms of the design of building as well as the interior, furniture and 
industrial products made him the modern design master of the 20th century.

\section{REFERENCES}

[1] Yi Xiao. Scandinavian Design Style and History [M].Wuhai: Wuhan University Press, 2005,83-100,145-215.

[2] Felix Solaguren-Beascoa. Danish Architect Arne Jacobsen [M].Shenyang: Liaoning Science and Technology Press, 2005,1325,158-163,211-213.

[3] Judith Miller.Miller's 20th Century Design [M].London:Octopus Publishing Group Ltd,2009,155-167.

[4] He Renke. The History of Industry Design (Third Edition) [M].Beijing: Higher Education Press, 2004,153-160 